\title{
Preparation, characterization of chitosan/bamboo charcoal/poly(methacrylate) composite beads
}

\author{
DOROTHY CAMINOS-PERUELO ${ }^{1,4, *}$, WEI-CHIEH WANG ${ }^{2}$, TSUNG-SHUNE CHIN ${ }^{3}$, \\ REGINA C SO ${ }^{4}$, RONALDO M FABICON ${ }^{4}$ and MING-FA HSIEH ${ }^{5}$ \\ ${ }^{1}$ Chemistry Department, Xavier University-Ateneo de Cagayan, 9000 Cagayan de Oro City, Philippines \\ ${ }^{2}$ ITRI South, Industrial Technology Research Institute, Tainan City 734, Taiwan \\ ${ }^{3}$ Department of Materials Science and Engineering, Feng Chia University, Taichung City 40724, Taiwan \\ ${ }^{4}$ Department of Chemistry, Ateneo de Manila University, 1108 Quezon City, Philippines \\ ${ }^{5}$ Department of Biomedical Engineering, Center for Nanotechnology, Chung Yuan Christian University, Taoyuan City \\ 32023, Taiwan \\ *Author for correspondence (dperuelo@xu.edu.ph)
}

MS received 14 September 2015; accepted 10 February 2017; published online 22 September 2017

\begin{abstract}
Preparation and characterization of a low-cost, novel steam-activated bamboo charcoal (BC) and poly(methacrylate) (PMAA) bound with chitosan (CTS) to form chitosan/bamboo charcoal/poly(methacrylate) (CTS/BC/PMAA) composite beads is reported for the first time in this paper. The characteristics are revealed by techniques such as X-ray photoelectron spectroscopy (XPS), thermal gravimetric analysis (TGA) and differential scanning calorimetry (DSC), scanning electron microscopy (SEM), Brunauer Emmett Teller (BET), solution $\mathrm{pH}$ and $\mathrm{pH}$ at point of zero charge $\left(\mathrm{pH}_{\mathrm{pzc}}\right)$. The composite beads possessed a dominant acidic surface group of $0.663 \mathrm{mmol} \mathrm{g}^{-1}$, as revealed by Boehm titration method. This acidity was confirmed by its solution $\mathrm{pH}$ of $6.46 ; \mathrm{pH}_{\mathrm{pzc}}$ of 6.70 and increase in oxygen surface via XPS analysis. $\mathrm{N}_{2}$ adsorption-desorption isotherms at $77 \mathrm{~K}$ of the beads revealed high BET surface area (SA) of $681.15 \mathrm{~m}^{2} \mathrm{~g}^{-1}$. Langmuir model affords a SA of $773.34 \mathrm{~m}^{2} \mathrm{~g}^{-1}$. SEM showed the microporous nature of the composite beads. The properties of CTS/BC/PMAA composite beads were compared to CTS/BC and neat BC. Thermal stability and successful coating of $5.1 \mathrm{wt} \%$ of PMAA and $6.8 \mathrm{wt} \%$ of CTS to CTS/BC/PMAA beads were shown by DSC and TGA analyses. The composite beads showed low carbon particle released at pH 7.4 and 6.8. Furthermore, dynamic adsorption revealed that CTS/BC/PMAA composite beads can be used to capture a polar substance, such as creatinine.
\end{abstract}

Keywords. Bamboo charcoal/chitosan/polymethacrylate; composite beads; characterization; pH point of zero charge; creatinine; column adsorbent.

\section{Introduction}

Bamboo plant has recently been considered as an important biomass resource material for the production of bamboo charcoal (BC) due to its low cost [1], eco-friendly attributes [2] and renewability [3]. $\mathrm{BC}$ has been used in various applications as adsorbent for the removal of organic [4] and inorganic [5] toxic contaminants from aqueous solutions [6], nanotechnology [3] and in biomedicine [7].

Chitosan (CTS) is a biodegradable, biocompatible and non-toxic polymer, which can be used as a coating material for $\mathrm{BC}$ to produce bamboo charcoal beads (BCBs) $[8,9]$. This composite has been published by our group as adsorbent for albumin and phenylalanine but there is no published work on the characterization of this composite $[6,8]$.
Acrylates like poly(methacrylate) (PMAA) have also been used as coating to pharmaceuticals and activated charcoal (AC) to produce smooth coating with great mechanical strength but readily accessible to polar, dissolved substances [10]. Furthermore, poly(methylmethacrylate), a biocompatible polymer [11], has been used to coat ACs together with CTS as adsorbent for extracorporeal filter cartridges for the removal of doxorubicin, a chemotherapeutic drug [12].

The advent of technology which can probe the surface and other properties have led to the characterization of these materials [9]. Vital to the development of adsorbent materials for various applications is the understanding of their properties as this information feeds into the fabrication and design as well as performance evaluation (e.g., adsorption capacity of the material) [9]. Typical techniques used to characterize

Electronic supplementary material: The online version of this article (doi:10.1007/s12034-017-1464-3) contains supplementary material, which is available to authorized users. 
composite material are based on the analysis of their surface area (SA), heat and mass difference of the material as it changed with temperature over time, morphology, etc. The properties and composition of $\mathrm{BC}$ can also be investigated using Boehm (acid/base) titration [13], elemental analysis, $\mathrm{pH}$ at point of zero charge $\left(\mathrm{pH}_{\mathrm{pzc}}\right)$ [14], immersion calorimetry [15], spectroscopy and others.

In this study, as-prepared $\mathrm{BC}$ derived from moso bamboo (phyllostachys pubescens) was combined with PMAA and bound with CTS to produce the composite beads. BC particles displayed an alkaline property $(\mathrm{pH} \mathrm{12)}$, hence its composite with PMAA and acidic solution of CTS can neutralize its alkalinity. Furthermore, BC particles can pose clinical risk of emboli in the blood vessels if used directly for haemoperfusion [8]. Hence, its composite with CTS can address this problem if used as adsorbent material for blood dialysis. Moreover, BC particles and BC/CTS composite preferentially adsorb L-phenylalanine $\left(35.5 \mathrm{mg} \mathrm{g}^{-1}\right)$ over bovine serum albumin $\left(3.4 \mathrm{mg} \mathrm{g}^{-1}\right)$ suggesting that the surface of BC and its composite with CTS is non-polar $[6,8]$. Its composite with PMAA rendered it more accessible to polar substance. In this study, a model polar molecule (creatinine) was used to adsorb to the composite beads. This composite material therefore is a three in one adsorbent material to address three problems. First, the alkalinity of $\mathrm{BC}$; second, the non-polar character of $\mathrm{BC}$ surface and third is the risk of emboli if used directly as adsorbent for blood dialysis. Hence, this study delves on the preparation and characterization of novel chitosan/bamboo charcoal-containing poly(methacrylate) composite beads (CTS/BC/PMAA). Its adsorption performance to creatinine was investigated using continuous dynamic adsorption for $4 \mathrm{~h}$. Its physico-chemical characteristics were investigated using techniques such as Xray photoelectron spectroscopy (XPS), thermal gravimetric analysis (TGA) and differential scanning calorimetry (DSC), scanning electron microscopy (SEM), SA and pore size distribution using Brunauer Emmett Teller (BET), solution $\mathrm{pH}$ and $\mathrm{pH}$ at $\mathrm{pH}_{\mathrm{pzc}}$. Furthermore, particle release experiment and equilibrium adsorption were also conducted.

\section{Experimental}

\subsection{Materials and characterization}

(please refer to supplementary information)

\subsection{Preparation of beads as adsorbent}

Briefly, three different beads were prepared; namely, CTS beads, CTS/BC, CTS/BC/PMAA beads.

2.2a Chitosan beads: Chitosan solution was prepared by mixing neat CTS powder in acetic acid $(2 \% \mathrm{w} / \mathrm{w})$. The mixture was stirred at $4^{\circ} \mathrm{C}$ for $8 \mathrm{~h}$ to produce a clear, viscous, homogeneous mixture of CTS, which was used in preparation of composite beads such as CTS/BC and CTS/BC/PMAA. The viscous solution was extruded via a syringe pump at a rate of $10 \mathrm{ml} \mathrm{h}^{-1}$, using an 18-gauge needle into a coagulation solution bath $(\mathrm{NaOH}:$ methanol, $3: 1 \mathrm{v} / \mathrm{v})$ at room temperature (RT). The resulting beads were washed with hot followed by cold deionized water until neutral $\mathrm{pH}$ of 6.9-7.1 of the washed solution. The beads were dried overnight at $65^{\circ} \mathrm{C}$ in a thermostated oven. The dried bead was denoted as CTS bead.

2.2b CTS/BC beads and CTS/BC/PMAA beads: For CTS/ BC beads: $1.5 \mathrm{~g}$ CTS $(2 \% \mathrm{w} / \mathrm{w})$ solution was mixed with 50 mg BC.

For the preparation of CTS/BC/PMAA beads: $1.5 \mathrm{~g}$ CTS solution was added to the premixed $50 \mathrm{mg} \mathrm{BC}$ and $15 \mathrm{mg}$ PMAA as shown in figure 1. The two types of mixtures were further stirred separately for $8 \mathrm{~h}$ at $4^{\circ} \mathrm{C}$. The resulting dispersions were also extruded through a syringe pump using the same procedure for CTS beads as described above.

\section{Results and discussion}

\subsection{Preparation}

3.1a Synthesis of PMAA and preparation of CTS/BC/PMAA beads: Poly(methacrylate)-co-ethylene glycol dimethacrylate was prepared using methacrylic acid (MAA) as the monomer and ethylene glycol dimethacrylate as the crosslinker. MAA has been shown to be a good monomer for creatinine adsorption. MAA is a versatile monomer of choice intended for various applications ranging from chromatographic packing to antibody mimics and molecular imprinting for creatinine [16-18]. This polymer was synthesized by bulk polymerization format via free radical using azo-bisisobutyronitrile as the initiating species.

Vital to the preparation of the beads is the dynamic viscosity of the mixture including its stirring time. The viscosity of the freshly prepared 2\% CTS solution was between 451 and $510 \mathrm{cP}$. This viscosity was maintained by stirring the mixture at $4-6^{\circ} \mathrm{C}$ upto $8 \mathrm{~h}$. The total stirring should not exceed 24 $\mathrm{h}$ because viscosity of acidic solution of CTS is affected by factors such as temperature and storage time [19]. Acidic solution of CTS is known to decrease in viscosity upon storage at RT due to hydrolysis and polymer degradation in acetic acid medium $[19,20]$. As a result, freshly prepared CTS solution was used to prepare the beads. The viscosity of the mixtures (CTS/BC and CTS/BC/PMAA) were between 603-606 and 698-725 cP, respectively. The average diameter of CTS/BC and CTS/BC/PMAA beads are 1.55 and $1.49 \mathrm{~mm}(n=50)$, respectively, using UPM digital caliper.

\subsection{Characterization}

3.2a Surface morphology: The SEM micrographs of the beads are shown in figures 2 and 3. Figure 2a shows the spherical bead and $2 b$ is a higher magnification of the bead. 

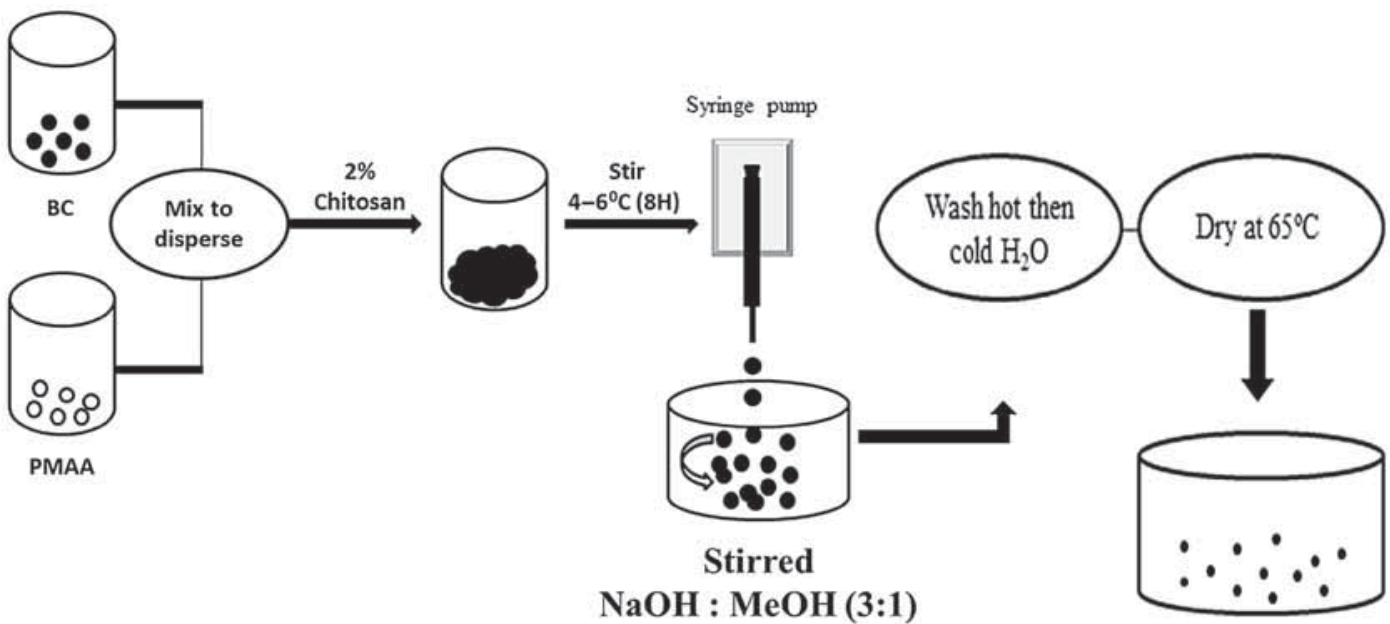

Dried CTS/BC/PMAA beads

Figure 1. Schematic representation for the fabrication of the composite beads. PMAA and BC were mixed with chitosan and stirred at $4-6^{\circ} \mathrm{C}$ for $8 \mathrm{~h}$ followed by extrusion through a syringe pump. The resulting beads were washed with hot water followed by cold water and dried in an oven.
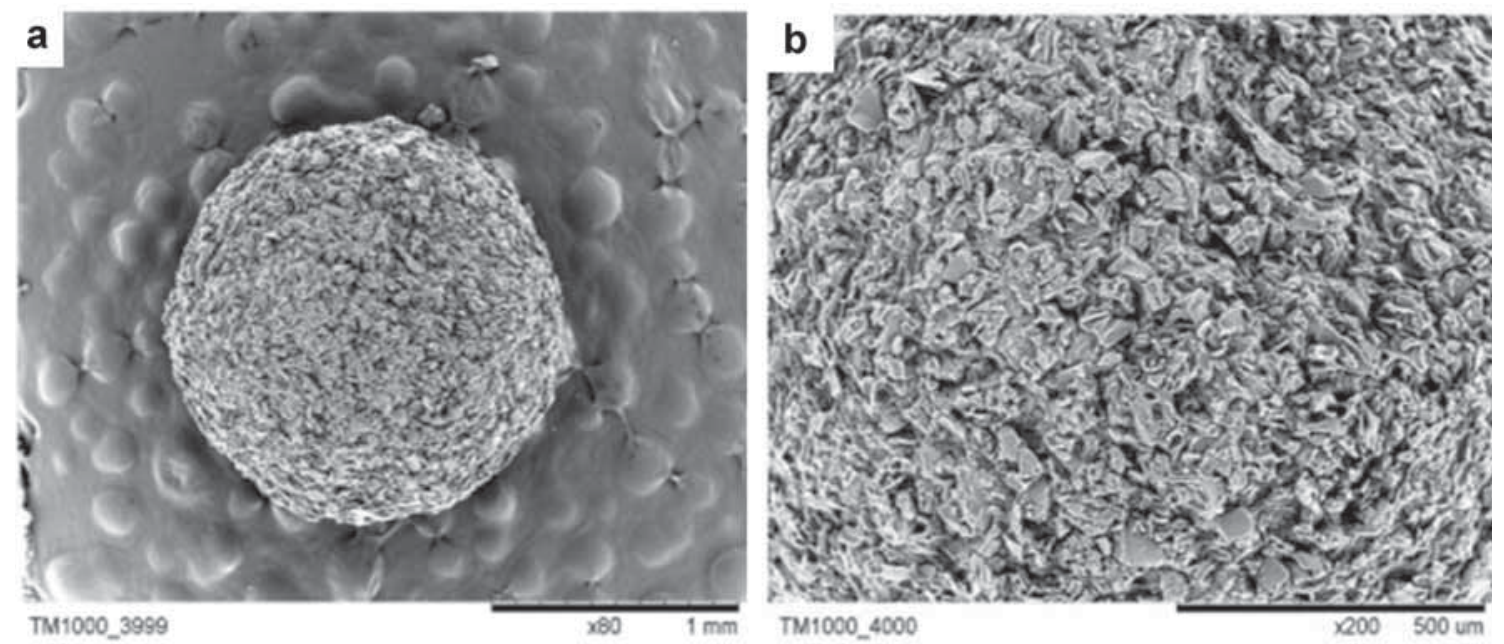

Figure 2. SEM images of the CTS/BC/PMAA spherical bead (a) at X80 and (b) X200 magnifications.

Surface morphology of BC (figure 3a) appeared heterogeneous with particles of different sizes and irregular shapes [21]. Macropores in BC are visible. PMAA (figure 3b) are more granulated and are regularly shaped. The CTS/BC and CTS/BC/PMAA beads do not have much difference with each other but textural change can be supported by the BET results in which mesoporous PMAA and CTS beads become microporous when combined with $\mathrm{BC}$.

Surface and cross-section (figure $3 \mathrm{c}-\mathrm{f}$ ) appeared homogeneous and uniform distribution of CTS and PMAA in the beads is observed in which individual components are not anymore distinguishable except for the macropores found in BC. The presence of macropores in the image justifies the effect of high temperature and increased time for activation that would result in pore widening. Steam-activated BC used in this study was prepared at high temperature $\left(850^{\circ} \mathrm{C}\right)$ and activated for 90 min similar to the report somewhere [22]. Treatment in these conditions resulted in widened pores because steam water reacts either on the pore walls or on the carbon surface during the first stages of activation. In addition, some authors reported that high temperature activation results in higher microporosity development and higher SA ( $\left.\mathrm{S}_{\mathrm{BET}}\right)$ until maximum is reached and it results in massive destruction of micropores and become mesopores [23-25]. These observations are supported by the BET results discussed in the next section.

3.2b Surface area, porosity and textural characteristics: $\mathrm{N}_{2}$ adsorption-desorption isotherms at $77 \mathrm{~K}$ of CTS/BC and CTS/BC/PMAA beads exhibited a specific SA, BET of 

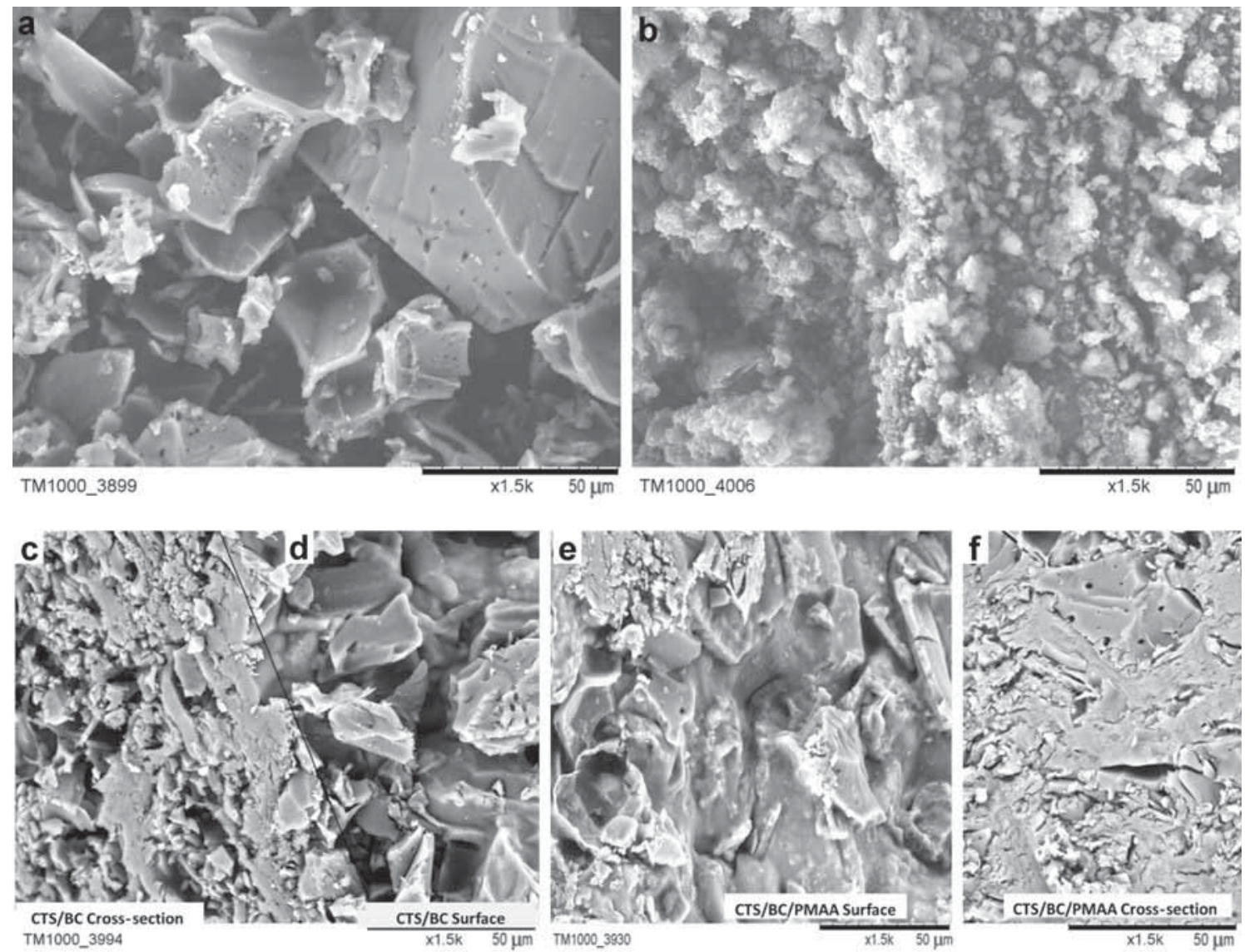

Figure 3. SEM images at higher magnifications: (a, b) BC and PMAA; (c, d) CTS/BC, (e, f) CTS/BC/PMAA surface and cross-section $(\mathrm{X} 1.5 \mathrm{~K})$. Image of cross-section was prepared by cutting liquid $\mathrm{N}_{2}$-frozen bead [10].

$658.83,681.15 \mathrm{~m}^{2} \mathrm{~g}^{-1}$, respectively. Langmuir model affords a SA of $873.70,773.34 \mathrm{~m}^{2} \mathrm{~g}^{-1}$ for the two composite beads, respectively. A decreased in SA when neat $\mathrm{BC}$ is combined with CTS and PMAA is observed. This reduction in SA is also reported somewhere [26]. Furthermore, pore size distribution of the two composite beads (CTS/BC and CTS/BC/PMAA) shown in figure $4 \mathrm{a}$ and $\mathrm{c}$ show higher occurrence of micropores with an average pore width of less than $2 \mathrm{~nm}$. The two beads show monolayer adsorption-desorption isotherms of $\mathrm{N}_{2}$ gas indicating Type I Langmuir isotherm as shown in figure $4 \mathrm{~b}$ and $\mathrm{d}$. This is a characteristic of materials with limiting uptake and narrow pore size distribution that are essentially microporous in nature [27]. There is a strong interaction between adsorbent and adsorbate where high adsorption at relatively low pressure can be observed. The plots also show finely divided surface with limited adsorption occurring as $P / P_{0}$ approach 1 . In addition, the close loop hysteresis further indicates a high amount of micropores, which confirms the Langmuir adsorption-desorption isotherm using $\mathrm{N}_{2}$ as adsorbed molecules.

3.2c Acid/base character of adsorbents: The total surface acids associated with carboxylic, phenolic and lactonic reacted with $\mathrm{NaOH}$ [28]. Conversely, total surface basicity, which are usually associated with pyrones, quinone, chomenes, ethers, carbonyl groups, pi-electron rich systems in the graphene sheets of the exposed graphene layers and other Lewis basic groups reacted with hydrochloric acid, determined by Boehm titration, which is shown in table $1[29,30]$.

BC exhibited a total surface basicity of $0.924 \mathrm{mmol} \mathrm{g}^{-1}$ and total surface acidity of $0.804 \mathrm{mmol} \mathrm{g}^{-1}$. The aqueous solution of $\mathrm{BC}$ confirmed the basic property as it possessed a $\mathrm{pH}$ of 10.25. This indicates presence of Lewis basic groups such as $\mathrm{C}-\mathrm{O}, \mathrm{C}=\mathrm{O}$, as well as the $\mathrm{C}=\mathrm{C}$ pi-electron rich system as confirmed by XPS, discussed in the next section. Furthermore, the $\mathrm{pH}_{\mathrm{pzc}}$ of $\mathrm{BC}$ is 8.37 , this is the $\mathrm{pH}$ at which the surface charge of $\mathrm{BC}$ is zero. For CTS/BC and CTS/BC/PMAA, the $\mathrm{pH}_{\mathrm{pzc}}$ was established at 6.81 and 6.70 , respectively. The decrease of $\mathrm{pH}_{\mathrm{pzc}}$ from 8.37 of neat $\mathrm{BC}$ to 6.81 and 6.70 for CTS/BC and CTS/BC/PMAA beads, respectively, implies the acidic property of the composite beads. Furthermore, neutralization of the basic functional groups found on $\mathrm{BC}$ with the protonated amino groups found in CTS and carboxyl groups $(\mathrm{COOH})$ in PMAA took place when composite beads were prepared. This becomes an advantage because the $\mathrm{pHs}$ of the composite beads are very close to the physiologic $\mathrm{pH}$ (7.4), which indicates the potential of this material for use in biomedical applications. 

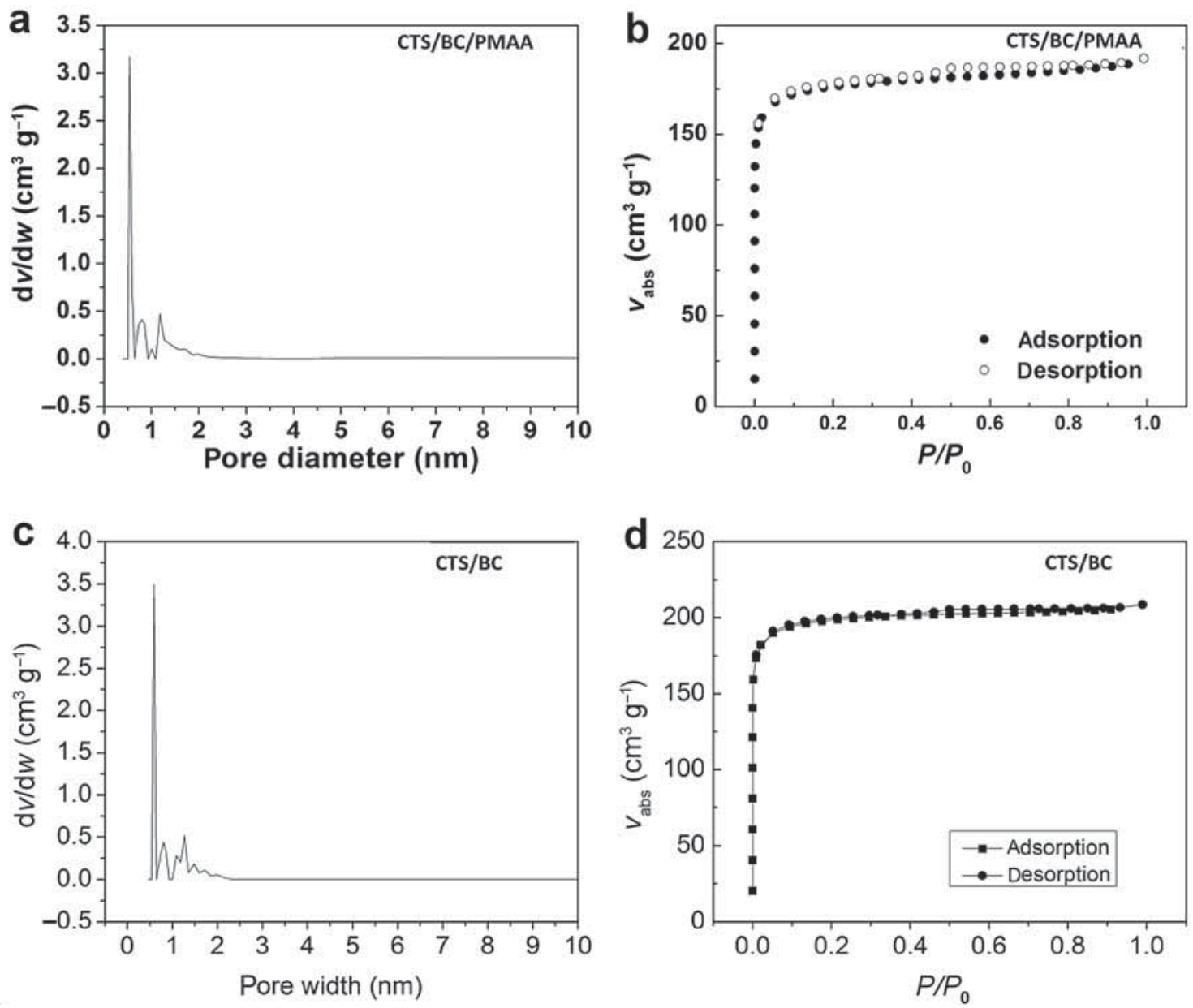

Figure 4. BET analysis of adsorbents (a) CTS/BC/PMAA pore size distribution, (b) CTS/BC/PMAA Langmuir $\mathrm{N}_{2}$ adsorption-desorption, (c) CTS/BC bead pore size distribution, (d) CTS/BC bead Langmuir $\mathrm{N}_{2}$ adsorption-desorption (IUPAC definition of micropores $<2 \mathrm{~nm}$, mesopores 2-50 $\mathrm{nm}$ and macropores $>50 \mathrm{~nm}$ ) [31].

Table 1. $\mathrm{pH}$ point of zero charge $\left(\mathrm{pH}_{\mathrm{pzc}}\right)$ and total surface acidity and basicity of adsorbents containing steamactivated $\mathrm{BC}$.

\begin{tabular}{lrcrr}
\hline Sample ID & pH solution & $\begin{array}{l}\text { Total surface basic groups } \\
\left(\mathrm{mmol} \mathrm{g}^{-1}\right)\end{array}$ & $\begin{array}{l}\text { Total surface acidic groups } \\
\left(\mathrm{mmol} \mathrm{g}^{-1}\right)\end{array}$ & $\mathrm{pH}_{\mathrm{pzc}}$ \\
\hline BC & $10.25 \pm 0.007$ & $0.924 \pm 0.036$ & $0.804 \pm 0.161$ & $8.37 \pm 0.007$ \\
CTS/BC & $6.46 \pm 0.007$ & $0.560 \pm 0.152$ & $0.594 \pm 0.118$ & $6.81 \pm 0.003$ \\
CTS/BC/PMAA & $6.46 \pm 0.014$ & $0.565 \pm 0.288$ & $0.663 \pm 0.105$ & $6.70 \pm 0.007$ \\
\hline
\end{tabular}

Total surface acidity/basicity: determined by Boehm titration.

BC, steam-activated bamboo charcoal; CTS/BC, chitosan/bamboo charcoal beads; CTS/BC/PMAA, chitosan/bamboo charcoal/polymethacrylate beads.

Calculations: Total surface basicity $=\mathrm{mmol}$ reacted with $\mathrm{HCl} /$ gram adsorbent.

Total surface acidity $=$ mmol reacted with $\mathrm{NaOH} /$ gram adsorbent.

3.2d Functional groups: XPS peaks of steam-activated $\mathrm{BC}, \mathrm{CTS} / \mathrm{BC}$ and $\mathrm{CTS} / \mathrm{BC} / \mathrm{PMAA}$ shown in figure 5 confirm the presence of $\mathrm{COO}, \mathrm{C}-\mathrm{O}$ and $\mathrm{C}=\mathrm{C}$ groups detected by Boehm titration. The surface binding state of $\mathrm{C} 1 \mathrm{~s}$ of the three adsorbents shows the presence of graphitic carbons, $\mathrm{COOH}$ or ester groups between 285 and $289 \mathrm{eV}$.
Results of deconvoluted $\mathrm{C} 1 \mathrm{~s}$ peaks of $\mathrm{BC}, \mathrm{CTS} / \mathrm{BC}$ and CTS/BC/PMAA showed three different spectral features that fit the $\mathrm{C} 1 \mathrm{~s}$ envelope, as shown in figure $5 \mathrm{c}$. One was the unmodified carbon $\mathrm{C}-\mathrm{C}$ and/or the $\mathrm{C}=\mathrm{C}$ at around 283.6$284.5 \mathrm{eV}$. Second, the two oxygen-containing carbons, C-O and $\mathrm{COO}$ at around $285.5-285.8 \mathrm{eV}$ and $288.0-289.0 \mathrm{eV}$, 

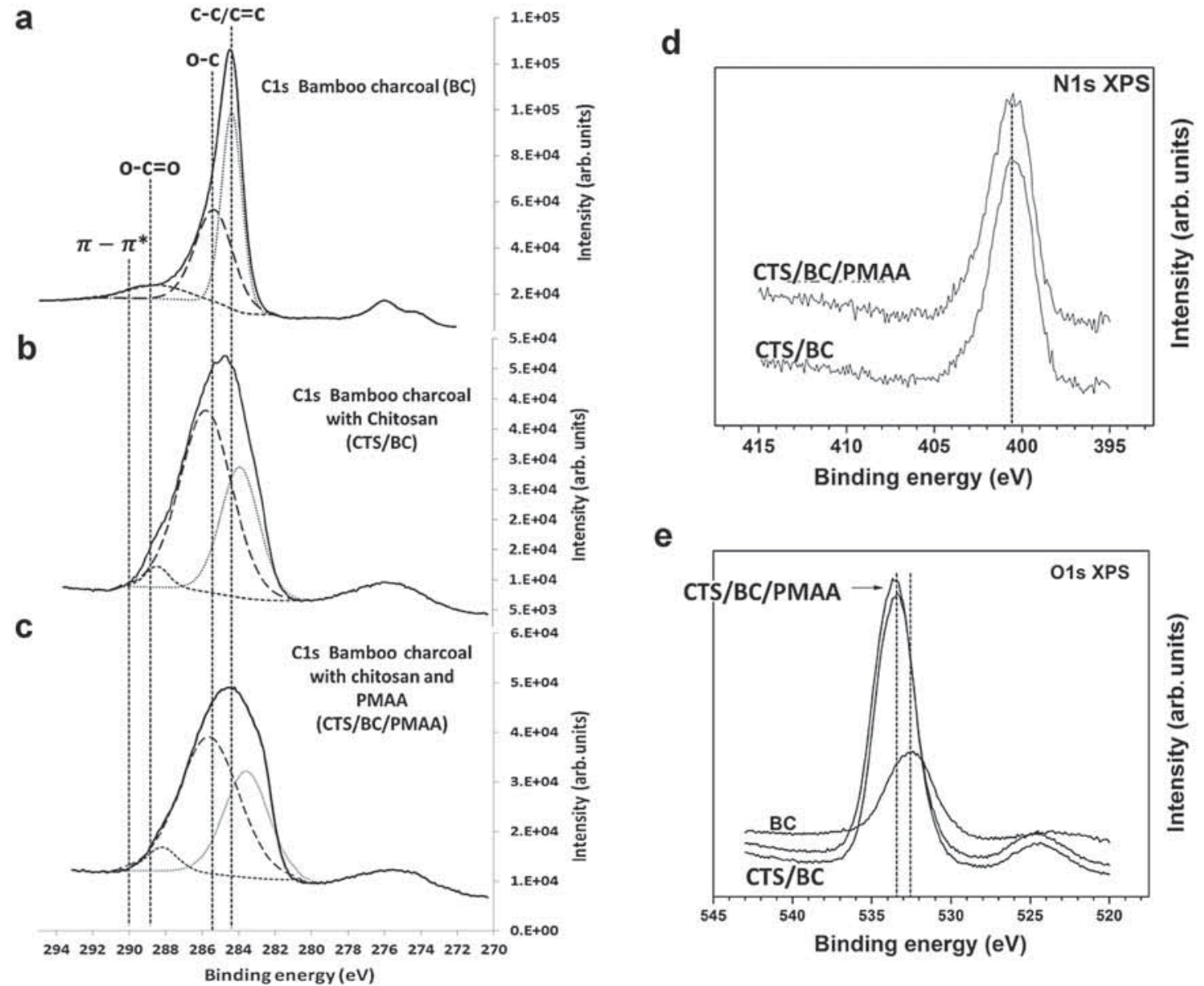

Figure 5. XPS peak fitting of deconvoluted $\mathrm{C} 1 \mathrm{~s}$ of (a) BC, (b) CTS/BC, (c) CTS/BC/PMAA and overlay XPS peaks of (d) N1s of CTS/BC and CTS/BC/PMAA and (e) O1s of BC, CTS/BC and CTS/BC/PMAA. No N1s peak was detected based on survey scan conducted on BC.

respectively [32]. The binding energy at $289.0 \mathrm{eV}$ is assigned to $\mathrm{O}-\mathrm{C}=\mathrm{O}$ was found broad in $\mathrm{BC}$. This peak has shifted to lower binding energy and became more pronounced (or sharper) in CTS/BC (288.5 eV) and CTS/BC/PMAA (288.0 $\mathrm{eV})$ composite beads. These shifts to lower binding energy are indicative of the interactions between $\mathrm{COO}$ of $\mathrm{BC}$ and/or PMAA and NH of CTS. The peak at $285.5 \mathrm{eV}$ is assigned to $\mathrm{C}-\mathrm{O}$ in $\mathrm{BC}$, this peak has shifted slightly higher binding energy in CTS/BC (285.6 eV) and CTS/BC/PMAA (285.8 $\mathrm{eV})$. These shifts to higher binding energy indicate increased $\mathrm{C}-\mathrm{O}$ in CTS/BC and CTS/BC/PMAA composite beads.

XPS for N1s and O1s showed typical features for microporous materials as shown in figure $5 \mathrm{~d}$ and e, respectively. $\mathrm{O} 1 \mathrm{~s}$ peaks revealed at $532.5-533.5 \mathrm{eV}$. The peak at $532.5 \mathrm{eV}$ found in $\mathrm{BC}$ has been slightly shifted to higher binding energy $(533.5 \mathrm{eV})$ for CTS/BC and CTS/BC/PMAA. This indicates increase in $\mathrm{O}$ content in the composite beads. Increase in oxygen content such as presence of $\mathrm{C}-\mathrm{O}$ and $\mathrm{O}-\mathrm{C}=\mathrm{O}$ has been suggested to be $\mathrm{COOH}$ responsible for the acidic nature of carbon as reported by some researchers $[33,34]$. The N1s peak at around $398-403 \mathrm{eV}$ found in the samples was found to be an $\mathrm{sp}^{2}$ or $\mathrm{sp}^{3}$ nitrogen.

3.2e Homogeneity and thermal stability: Figure 6a displayed a sharp endothermic melting temperature, $T_{\mathrm{m}}$ peak at $74.6^{\circ} \mathrm{C}$ of neat PMAA indicating a relatively uniform molecular weight, MW within the sample [35].

Conversely, CTS beads showed no endothermic peak for loss of water near $79^{\circ} \mathrm{C}$ indicating that the sample was anhydrous [36]. While an exothermic peak appeared at $303^{\circ} \mathrm{C}$, which corresponds to the degradation temperature of CTS $\left(T_{\mathrm{CTS}}\right)$. This has been previously reported somewhere [36-38].

In $\mathrm{CTS} / \mathrm{BC}$ composite, an endothermic peak was apparent at $70.1{ }^{\circ} \mathrm{C}$, indicating the loss of water in the sample. In CTS/BC/PMAA composite bead, the $T_{\mathrm{CTS}}$ of CTS was observed at a reduced peak area $(2350 \mathrm{~mJ}$ of CTS to 1981.14 $\mathrm{mJ}$ of CTS/BC/PMAA). The decrease in $T_{\mathrm{m}}\left(66.77^{\circ} \mathrm{C}\right)$ for CTS/BC/PMAA beads as compared to $T_{\mathrm{m}}\left(71.6^{\circ} \mathrm{C}\right)$ of 
a

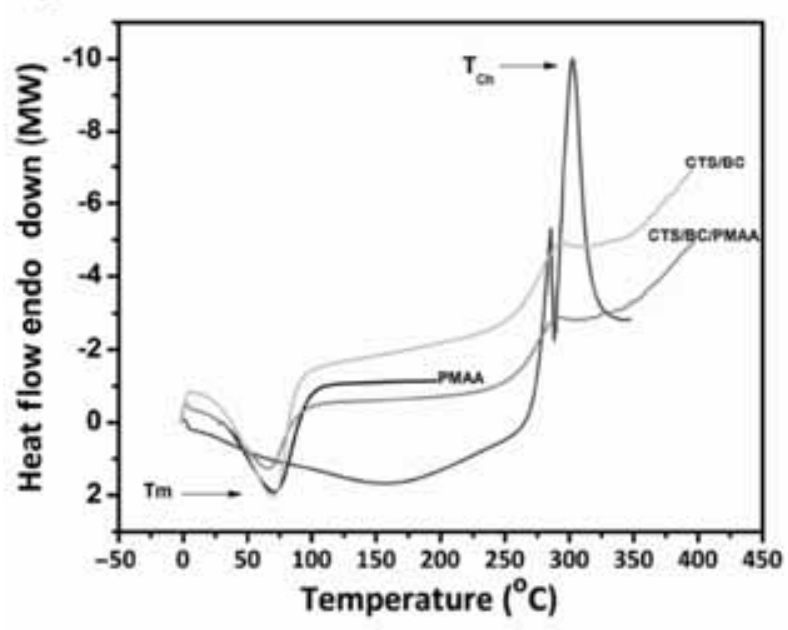

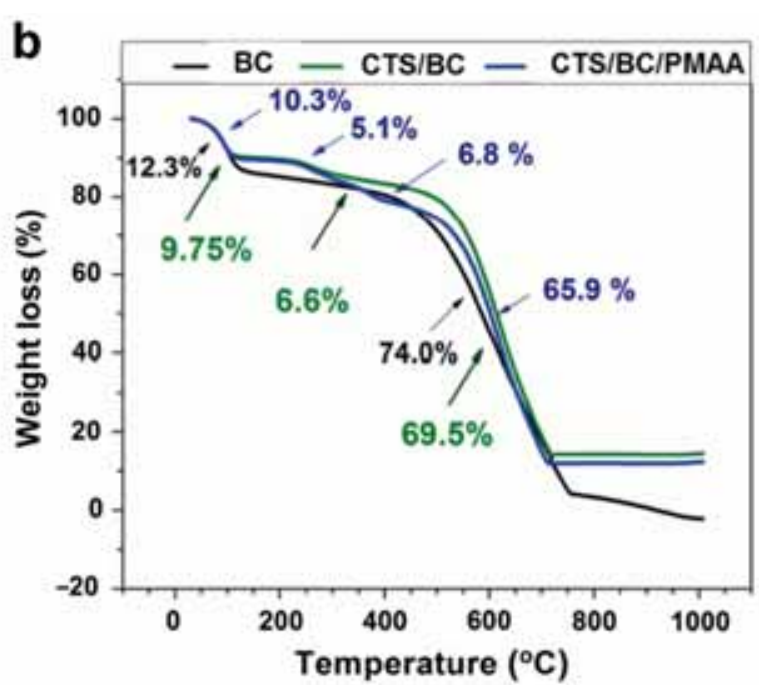

Figure 6. (a) DSC thermogram of neat PMAA, CTS beads, CTS/BC and CTS/BC/PMAA composites, as obtained by heating from -50 to $450^{\circ} \mathrm{C}$ at a rate of $2^{\circ} \mathrm{C} \mathrm{min}^{-1}$. (b) TGA of BC (black curve), CTS/BC (green curve) and CTS/BC/PMAA (blue curve).

neat PMAA could be due to CTS and PMAA polymerpolymer interaction and morphological effects as previously reported somewhere $[39,40]$. Furthermore, this polymerpolymer interaction directly influences the miscibility of the two polymers, which was successfully described by the binary interaction model where the presence of hydrogen bonding, electrostatic and dipole-dipole as the most common intermolecular interactions occurring between two different polymer chains $[39,40]$. In this case, electrostatic interaction between the protonated amino $\left(\mathrm{NH}_{3}^{+}\right)$groups in CTS and negatively charged $\mathrm{COO}^{-}$of PMAA. H-bonding as well as hydrophobic interactions between non-polar moiety of CTS and PMAA could also be possible in the composite beads. These interactions are demonstrated by the depression of $T_{\mathrm{m}}$ from 71.6 of PMAA to 66.77 of CTS/BC/PMAA [41].

Figure $6 \mathrm{~b}$ shows the thermal degradation and stability of BC-containing adsorbents using TGA under air atmosphere. All three adsorbents revealed weight loss of adsorbed and bound water at around $29^{\circ} \mathrm{C}$ of $12.3,9.75$ and $10.3 \%$ for $\mathrm{BC}$, CTS/BC and CTS/BC/PMAA, respectively. BC exhibited the highest loss $(12.3 \%)$ of adsorbed and/or bound water. This may be due to its powdery structure and microporous nature, which was highly adsorbent compared to the bead format. CTS/BC/PMAA displayed a higher water loss of $10.3 \%$ compared to CTS/BC of $9.75 \%$. The addition of PMAA to form CTS/BC/PMAA, resulted in its ability to adsorb more water as it exhibited higher water loss. This is due to the addition of $\mathrm{COOH}$, which can H-bond with water. CTS in CTS/BC and CTS/BC/PMAA beads exhibited two main decomposition stages [39].

In CTS/BC beads, CTS started to decompose at temperature between 100 and $382^{\circ} \mathrm{C}$ and completely burnt at $724^{\circ} \mathrm{C}$ while that in CTS/BC/PMAA, it started to decompose at $306-465^{\circ} \mathrm{C}$ and completely burnt at $746^{\circ} \mathrm{C}$. The decomposition temperature of CTS/BC/PMAA is higher than CTS/BC.
Table 2. Carbon particle release data.

\begin{tabular}{ccccc}
\hline & \multicolumn{4}{c}{ Absorbance unit } \\
\cline { 2 - 5 } $\mathrm{pH}$ & CTS/BC & CTS/BC/PMAA & $\begin{array}{l}\text { Morley and } \\
\text { Chang* }\end{array}$ & Chandy** \\
\hline 7.4 & 0.0197 & 0.0052 & 0.006 & 0.0055 \\
6.8 & 0.001 & 0.001 & - & - \\
\hline
\end{tabular}

*Using collodion-coated petroleum pitch [42]; **using chitosan-coated AC [43].

This means that CTS/BC/PMAA composite beads possessed higher degree of thermal stability compared to CTS/BC. Furthermore, results indicated that $5.1 \mathrm{wt} \%$ of PMAA has been coated to CTS/BC/PMAA and 6.6 and $6.8 \mathrm{wt} \%$ of CTS has been coated to CTS/BC and CTS/BC/PMAA, respectively. This means that a successful coating of CTS and PMAA has been done to $\mathrm{BC}$.

3.2f Carbon particle release: The carbon particle release at $\mathrm{pH} 7.4$ and 6.8 for CTS/BC/PMAA composite beads afford an absorbance reading of 0.00525 and 0.001 absorbance units, respectively. The values are lower than the particle release reported by Morley and Chang (0.006 absorbance units) and Chandy (0.0055 absorbance units), both at $\mathrm{pH} 7.4$ as shown in table $2[42,43]$. This indicated that the presence of PMAA in CTS/BC/PMAA rendered the material to be mechanically sturdy with lesser carbon particle release.

Since CTS/BC/PMAA beads showed low carbon particle release, the composite beads were used as column packing for a flow-through experiment for $4 \mathrm{~h}$ of simulating dialysis time. Results (figure 7) show that the amount of creatinine adsorbed ( $\mathrm{mg} \mathrm{g}^{-1}$ and \%), decreased as time lapsed upto $4 \mathrm{~h}$.

After 30 min the amount of creatinine adsorbed was 0.22 $\mathrm{mg} \mathrm{g}^{-1}$ equivalent to $27.3 \%$ of the total creatinine, after $4 \mathrm{~h}$ 


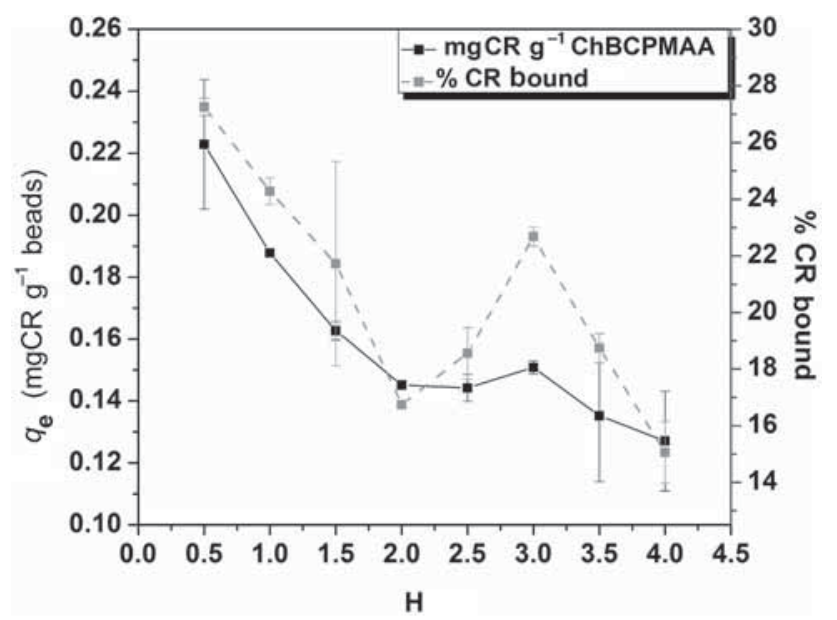

Figure 7. Dynamic adsorption of creatinine (CR) to CTS/BC/PMAA for $4 \mathrm{~h}$ continuous flow through of $100 \mathrm{mg} \mathrm{l}^{-1}$ creatinine (at $\mathrm{pH} 7$ in phosphate buffer) using a peristaltic pump at a flow rate of $5 \mathrm{ml} \mathrm{min}-1$.

of dialysis, amount of creatinine adsorbed decreased to 0.13 $\mathrm{mg}$ creatinine per gram beads equivalent to $15.1 \%$ of the total creatinine. A decrease of about $12 \%$ from 0.5 to $4 \mathrm{~h}$ of dialysis using only $40 \mathrm{mg}$ beads. This indicates that the saturation point of the adsorbent has not yet been achieved after $4 \mathrm{~h}$ of dialysis. This shows that the composite beads can be used as column adsorbent for haemoperfusion application to remove toxic creatinine from the aqueous medium.

\section{Conclusion}

The preparation and characterization of the adsorbent composed of BC, CTS and PMAA to form CTS/BC/PMAA beads was ellucidated in this research. BET and Langmuir analyses revealed high SA of 681.15 and $773.34 \mathrm{~m}^{2} \mathrm{~g}^{-1}$, respectively. The beads showed high occurrence of micropores with pore diameter of less than $2 \mathrm{~nm}$. The Boehm titration showed acidic surface of $0.663 \pm 0.105 \mathrm{mmol} \mathrm{g}^{-1}$ of CTS/BC/PMAA beads and $\mathrm{pH}_{\mathrm{pzc}}$ of 6.70 . The aqueous solution showed acidic character having a $\mathrm{pH}$ of 6.46 . The solution $\mathrm{pH}$ and $\mathrm{pH}_{\mathrm{pzc}}$ are close to the physiological $\mathrm{pH}$ 7.4, which becomes an advantage to further explore the material for biomedical applications. The uniform distribution of CTS and PMAA in the composite beads was revealed by SEM. Successful coating of PMAA and CTS to neat BC was revealed by TGA, $5.1 \mathrm{wt} \%$ of PMAA has been coated to CTS/BC/PMAA and $6.8 \mathrm{wt} \%$ of CTS has been coated to CTS/BC/PMAA. The coating of the $\mathrm{BC}$ with PMAA and CTS rendered the composite beads with mechanical strength as indicated by low carbon particles released in the solution.

Dynamic adsorption showed a decrease of only $12 \%$ from 0.5 to $4 \mathrm{~h}$ of dialysis. This showed that the saturation point of the beads have not yet been achieved after $4 \mathrm{~h}$ of dialysis. Hence, the potential of CTS/BC/PMAA composite beads is essential for the capture of an aqueous substance such as creatinine.

The use of biomass-derived activated charcoal obtained from plant source such as bamboo offers a number of advantages because it is renewable, ease of access and low price, hence this composite material composed of BC and PMAA bound with CTS is a potential column adsorbent for various applications.

\section{Acknowledgements}

We would like to thank the Ministry of Science and Technology, Taiwan, for financial support under grant numbers NSC101-2632-M-033-001-MY2 and NSC102-2632-M-033001-MY3. DCP would like to personally thank Prof. Rafael Luque, Dr Manuel Ojeda Rodríguez, Rick Arneil Arancon of the Universidad de Cordoba, Spain; Prof. Clovia Holdsworth, University of New Castle, Australia; Dr Juliet Dalagan, JP Garcia, Jennifer Mendez and last but not the least the Commission on Higher Education (CHED), for the scholarship and sandwich programme grant.

\section{References}

[1] Li Y, Shao J, Wang X, Deng Y, Yang H and Chen H 2014 Energy Fuels 285119

[2] Lei H, Wang Y and Huo J 2015 Micropor. Mesopor. Mat. 210 39

[3] Zhu J, Jia J, Kwong F L, Ng D H L and Tjong S C 2012 Biomass Bioenergy 3612

[4] Mohan D, Sarswat A, Ok Y S and Pittman C U Jr 2014 Bioresour. Technol. 160191

[5] Lou C W, Lu C T, Lin C W, Chen A P, Jang S B and Lin J H 2012 J. Eng. Fiber. Fabr. 7109

[6] Hsieh M F, Wen H W, Shyu C L, Wang W C and Chen W C 2007 J. Med. Biological Eng. 2747

[7] Chen K S, Chou C Y, Liao S C, Wu H M and Tsai H T 2012 Biomed. Eng.: Appl. Basis Commun. 24171

[8] Hsieh M F, Wen H W, Shyu C L, Chen S H, Li W T, Wang W C et al 2010 J. Biomed. Mater. Res. Part A 941133

[9] Grainger D W and Castner 2011 In: P Ducheyne, K Healy, D Hutmacher, D Grainger, C J Kirkpatrick (eds). Methods of analysis, vol 3, p 2

[10] Elkheshein S, Zia H, Needham T E, Badaway A and Luzzi L A 1992 J. Microencapsul. 941

[11] Jager M and Wilke A 2003 J. Biomater. Sci., Polym. Ed. 14 1283

[12] Miao J, Zhang F, Takieddin M, Mousa S and Linhardt R J 2012 Langmuir 284396

[13] Bach M T 2007 Ph.D. Thesis, University of Florida

[14] Lei L, Quinlavan P A and Knappe D R U 2002 Carbon 40 2085

[15] Moreno-Castilla C 2000 Carbon 381995 
[16] Sreenivasan K R S 1997 J. Appl. Polym. Sci. 662539

[17] Subrahmanyam S, Sergey A Piletsky, Elena V Piletska, Beining Chen, Kal Karim and Anthony P F Turner 2001 Biosens. Bioelectron. 16631

[18] Spivak D A 2005 Adv. Drug Deliv. Rev. 571779

[19] El-Hefian E A, Elham S Elgannoudi, Azizah Mainal and Abdul Haamid Yahaya 2010 Turk. J. Chem. 3447

[20] El-Hefian E A, Khan R A and Yahaya A H 2008 J. Chem. Soc. Pak. 30529

[21] Suthamnoi S K 2009 J. Metals Mater. Minerals 199

[22] Roman S, Gonzalez J F, Gonzalez-Garcia C M and Zamora F 2008 Fuel Process. Technol. 89715

[23] Rodríguez Reinoso F, Molina-Sabio M and González M T 1995 Carbon 3315

[24] Carrot P J M and Freeman J J 1991 Carbon 29499

[25] Tomków K, Siemieniewska T, Czechowski F and Jankowska A 1977 Fuel Process. Technol. 56121

[26] Miao J, Zhang F, Takieddin M, Mousa S and Linhardt R J 2012 Langmuir 284396

[27] Huzzein M Z, Tarmizi R S H, Zainal Z and Ibraiiim R 1996 Carbon 341447

[28] Al-Degs Y 2000 Wat. Res. 34927

[29] Rodríguez-Reinoso F, Molina-Sabio M and González M T 1995 Carbon 3315
[30] Boehm H P 1996 Adv. Catal. 16179

[31] McCusker L B, Liebau F and Engelhardt G 2001 Pure Appl. Chem. 73381

[32] Laszlo K, Tombacz E and Josepovits K 2001 Carbon 39 1217

[33] Laszlo K and Szucs A 2001 Carbon 391945

[34] Dambies L, Domard T V A and Guibal E 2001 Biomacromol. 2 1198

[35] Turner N W, Holdsworth C I, Donne S W, Mc Cluskey A and Bowyer M C 2010 New J. Chem. 34686

[36] El-Hefian E A, Elgannoudi E S, Mainal A and Yahaya A H 2008 J. Chem. Soc. Pak. 30529

[37] Sakurai K M T and Takahashi T 2000 Polymer 417051

[38] Zeng M F and Xu C 2004 J. Membr. Sci. 230175

[39] Al-Rawajfeha A E and Al-Rhael I 2006 Jordan J. Chem. 1 155

[40] Wan M W, Kan C C, Rogel B and Dalida M 2010 Carbohyd. Polym. 80891

[41] Landry M R M, Landry C J T, Teegarden D M, Colby R H, Long T E and Henrichs R M 1994 J. Appl. Polym. Sci. 54 991

[42] Morley D and Chang T 1987 Biomat. Art. Cells Art. Org. 15 617

[43] Chandy T and Sharma C P 1993 J. Microencapsul. 10475 